\title{
Performance Evaluation Of The Hydropower Plants Using Various Multi-Criteria Decision-Making Techniques
}

\author{
Sushrut H. Vinchurkar, B. K. Samtani
}

Abstract: Annual growth of $2.3 \%$ since 1990 to 2017 in the hydropower sector in India indicates it holds a vital position in the growth of electricity generation in the country. For effective and efficient running of the hydropower projects, maintenance schedules and performance evaluation have to be done. Thus, this paper presents the performance evaluation of four different hydro-powerhouses belonging to a different class. Multi-criteria decision making (MCDM) method stepwise weight assessment ratio analysis (SWARA) is used to calculate the weights. The weights calculated by SWARA are employed to assess the performance scores or ranks of Indira Sagar Project (ISP), Canal Head Power House (CHPH) and River Bed Power House (RBPH) at Sardar Sarovar Narmada Nigam Ltd. (SSNNL) by integrating SWARA with the MCDM techniques like weighted aggregate sum product assessment (WASPAS), technique for order of preference by similarity to ideal solution (TOPSIS) and preference ranking organization method for enrichment evaluation (PROMETHEE). A comparative analysis of these integrated methods is presented for improved future studies in the area of decision making. The results in this paper show performance rankings of the available alternatives, calculated using integrated SWARA-WASPAS, SWARA-TOPSIS and SWARA-PROMETHEE methods. Performance ranks obtained by SWARA-WASPAS and SWARA-TOPSIS methods are in the order ISP, RBPH, CHPH and LSPH, which shows similarity with the on-field performances and are well suited for the performance evaluation of hydropower projects.

Keywords: Performance evaluation, MCDM, SWARA, WASPAS, TOPSIS, PROMETHEE.

\section{INTRODUCTION}

Energy is the central requisite as well as a major contributing factor for balanced economic growth and social security of a country. Energy holds a significant position in the continuous improvement of technology, urbanization, industrialization and increases in the population, the necessity and demand for the power raise progressively [1]. Many countries are working in the direction of developing new procedures in accordance to encounter the increase in

Revised Manuscript Received on October 30, 2019.

* Correspondence Author

Sushrut H. Vinchurkar*, Department of Civil Engineering, Sardar Vallabhbhai National Institute of Technology, Surat, India. Email: sushrutvinchurkar@gmail.com +91-9630964486

B. K. Samtani, Professor, Department of Civil Engineering, Sardar Vallabhbhai National Institute of Technology, Surat, India. Email: samtanibk1956@gmail.com

(C) The Authors. Published by Blue Eyes Intelligence Engineering and Sciences Publication (BEIESP). This is an open access article under the CC BY-NC-ND license (http://creativecommons.org/licenses/by-nc-nd/4.0/) energy demand and reviewing their present strategies with the scope of sustainability. Since, the growth in energy demand has a direct effect on environmental, economic and social aspects, it is necessary to draw energy policies based on relevant effects [2].

India has numerous types of energy resources, such as coal, biomass and waste, petroleum and other petroleum product, natural gas, nuclear, hydroelectric and other renewable resources. Climate change and global warming and are the utmost thoughtful problems for developing countries. Thus, inexpensive power generation with a small amount of release of greenhouse gases is essential for developing countries as well as the world [3]. Hydro-energy is reflected as the non-conventional, non-polluting and environment-friendly source of energy [4]. With the features of low-cost energy generation, the minimum yield of pollution and prompt starting or shutting makes it one of the most likely renewable energy resource [5]. International Energy Agency (IEA) claims that India's energy use is expected to get double by 2040, with firmest progression rate, Nuclear (3\% yearly) and Renewable (2.3\% yearly, only for hydro) will perform an important role in the growth of electricity generation in India and worldwide up till 2040 [6].

The performance evaluation of hydropower plants is a multiple-criteria decision-making (MCDM) process due to considerations of various criteria. Decision making often becomes a difficult and tiresome job, especially when it is essential to find the best suitable alternative or to assign ranks amongst the available alternatives. The technique of MCDM is involved in organizing, making decisions and scheduling problems comprising multiple criteria. The motive of these methods is to, encounter these problems and ease the job of decision-makers. Normally, when an exclusive ideal solution for these problems is not available and it is required by the decision or policymaker for preference and differentiating between solutions [7].

The quest for the evaluation of performance along with the effective and efficient operation of hydropower plants has been addressed in numerous papers. Like, [8] developed a system for the evaluation of performance and optimize the energy for the real-time functioning of Itá Hydropower Plant, located in the south of Brazil, considering only outflows of turbine, head, losses and efficiencies. 
[9] used the specifications and procedure for the field performance test of turbines provided in Performance Test Code 18 (PTC 18): Hydraulic Turbines prescribed by American Society of Mechanical Engineers (ASME) and performance testing code ICE 41 (1991) suggested by International Electrotechnical Commission (IEC) and have considered load, discharge, net head and hydraulic power and mechanical power and efficiency for the performance evaluation of Zho Suwei run-of-river (ROR) type small hydropower project in Douliou, Taiwan [10] recommended a model comprised of MCDM techniques, multiple regression and ANN for the performance evaluation of small hydro projects in different locations of India considering energy, water availability, environmental aspect, transportability, proximity from the grid and accessibility as the criteria for performance evaluation. [11] Proposed and validated a model through the technique for order preference by similarity to the ideal solution (TOPSIS) for the assessment of parameters for optimum operation of small hydropower plants considering head, discharge, and head loss, the uncertainty of efficiency, efficiency, penstock diameter, guide vane opening and number of turbines. [12] Proposed a combined goal programming (GP) model using the approach of analytical hierarchy process (AHP) and TOPSIS for nine evaluation criteria for a big scale hydropower project located in Turkey. [13] Developed computational models for comparing the performances of two ROR hydropower plants by measuring transitory pressures at different points. [3] Evaluated the performance of different types like fossil fuel, geothermal, wind, hydro and gas power plants in Turkey using the fuzzy-TOPSIS technique, for the criteria like efficiency, cost of installation, and cost of electricity, $\mathrm{CO}_{2}$ emission and societal approval. [14] Presented a comprehensive analysis of hydropower plants in Canada and have considered the capability of power generation, profits, and ecological benefits along with community concern using the TOPSIS method. [15] Suggested the relevance and extension of MCDM methods for the stochastic inputs, with a relative study of different MCDM methods for the selection of the best location for wind turbines.

This paper proposes the performance evaluation of four different types of existing hydropower plants i) Indira Sagar Hydropower Project (1000 MW), ii) river-bed type viz. Sardar Sarovar Narmada Nigam Ltd. river bed power-house (1200 MW) and iii) canal head type canal head power-house (250 MW) and iv) ROR type Lower Sileru Power House (460 MW) using different MCDM methods.

The innovation in this research comprises of comparative analysis of intellectual techniques of MCDM for the first time to evaluate the performance ranks of existing hydropower projects, which may or may not belong to a different type. For the calculation of weights, SWARA method has been adopted and integrated approaches have been used for assigning them performance ranks using various methods of MCDM techniques. The remaining paper is organized as follows. Section 2 presents the methodology and detailed procedures of MCDM methods namely, stepwise weight assessment ratio analysis (SWARA), weighted aggregates sum product assessment (WASPAS), TOPSIS, and preference ranking organization method for enrichment evaluation (PROMETHEE). The portrayal of the study areas and results are revealed in Section 3. The results and discussions and conclusions are made in Section 4 and Section 5 respectively.

\section{METHODS AND METHODOLOGY}

Reasonably, numerous approaches are available for solving MCDM problems. The employability of MCDM is presented in this section and is as follows; renewable energy commissioning and planning, allocation of resources, building construction and management, transportation and traffic management, planning and designing of energy schemes, electricity service planning and scheduling and other various areas. The MCDM methods being applied to the designing and planning of energy are discussed in the following paragraphs.

\section{A. Stepwise weight assessment ratio analysis (SWARA)}

The SWARA technique was presented by Keršulien e et al. in 2010, using a diverse model in the field of MCDM. It was recognized for its usefulness in decision-making procedures in which stresses on strategy building rather conventional practices of decision-making [16]. SWARA offers specialists an acute part in the valuation of alternatives and criteria weights. The merit of SWARA is that each one of the experts identifies the prominence of individual criterion. Subsequently, having a clear idea to assess the alternatives from initial to latter, considering the consequences and ill effects. The contained knowledge of the expert, understanding and information about the alternatives simplify the procedure of decision-making. SWARA offers the following benefits over other weighing techniques; (i) ability to assess experts' view around the significant proportion amongst the alternatives in the course of weight determination, (ii) it is unfussy, comprehensible and direct where experts may work with ease. and (iii) additional advantage of this technique is that it studies the problem on the basis of company policies [17], [18] and [19]. The procedure to determine weights by SWARA is given as below:

Step 1: To decide the prominence of each criterion, the verdict from the ' $r$ ' experts is taken here. The criteria are organized in decreasing order on the basis of their probable impact and obtained scores.

Step 2: Obtaining ranks form the experts

For statistical dispensation interview with the experts is done. The ranking for $\mathrm{j}$ criterion, from the $\mathrm{k}$ respondent, is denoted by $t_{j k}$. The average attribute value for the total number of respondents $r$ is then determined for all the ranks using (1),

$$
\bar{t}_{j}=\left(\sum_{k=1}^{r} t_{j k}\right) / r
$$

Step 3: Identification of the weights $\left(q_{j}\right)$

The weights of the available criteria are obtained as (2) where; $\bar{t}_{j}$ is the average value of each criterion and $t_{j}$ is the sum of the criterion's priority values

$$
\begin{gathered}
q_{j}=\bar{t}_{j} / \sum_{j=1}^{n} t_{j} \\
\sum_{j=1}^{n} q_{j}=1
\end{gathered}
$$

The weights so obtained from (1) and (2) are checked for their relevance and quality, by dispersion (3) and variation (4) in the expert ranking; 
Dispersion of expert scores

$$
\sigma^{2}=\frac{1}{r-1} \sum_{k=1}^{r}\left(t_{j k}-\bar{t}_{j}\right)^{2}
$$

Variation of expert scores

$$
\beta_{j}=\sigma / \bar{t}_{j}
$$

\section{Step 4: Reliability of the data}

The consistency of the scores is determined by the coefficient of concordance, $\mathrm{W}$ and shown in (5).

$$
W=\frac{12 S}{r^{2}\left(n^{3}-n\right)-r \sum_{k=1}^{r} T_{k}}
$$

(6)

$$
S=\sum_{j=1}^{n}\left[\sum_{k=1}^{r} t_{j k}-\frac{1}{n} \sum_{j=1}^{n} \sum_{k=1}^{r} t_{k j}\right]^{2}
$$

But, the value of $\mathrm{W}$ obtained by (5) is stochastic in nature, thus, the significance of the coefficient of concordance must be derived. Kendall showed that when $\mathrm{n}$ is greater than 7 , distribution with the degrees of freedom $(\vartheta)$ must be taken as $\vartheta=\mathrm{n}-1$.

$\chi_{\alpha, \vartheta}^{2}=W \cdot r \cdot(n-1)$

Step 5: Comparative significance of criteria

Starting with the second criteria, the expert states the comparative significance of criterion $j$ with respect to the previous $(j-1)$ attribute, for all individual attributes, this ratio is known as the comparative importance of the average value and is denoted as $s_{j}$.

Step 6: Coefficient for recalculation of weights

The coefficient $k_{j}$ is determined for the reassessment of weights is obtained as (8)

$$
k_{j}=\left\{\begin{array}{cc}
1 & j=1 \\
s_{j}+1 & j>1
\end{array}\right.
$$

Step 7: Recalculation of weights

Recalculated weights are obtained by (9)

$q_{j}=\left\{\begin{array}{cc}1 & j=1 \\ \frac{k_{j-1}}{k_{j}} & j>1\end{array}\right.$

Step 8: Relative weights $\left(\mathrm{w}_{\mathrm{j}}\right)$

For evaluation of alternatives, the recalculated weights are calculated from (10)

$w_{j}=\frac{q_{j}}{\sum_{j=1}^{n} q_{j}}$

\section{B. Weighted aggregates sum product assessment (WASPAS)}

WASPAS technique was developed by [20]. This method is a combination of the two MCDM methods, namely the weighted sum model (WSM) and weighted product model (WPM). The steps involved in WASPAS methods are as following:

Step 1: To prepare normalized decision matrix

If the optimum value is to be maximized

$\bar{X}_{i j}=\frac{X_{i j}}{\max _{i j}}$

If the optimum value is to be minimized

$\bar{X}_{i j}=\frac{\min X_{i j}}{X_{i j}}$
Step 2: Calculation of WASPAS weighted matrix for summarizing and multiplication part

a) $\quad$ For summarizing part
$Q_{i j}^{(1)}=\sum_{j=1}^{n} w_{j} \bar{x}_{i j}$

For multiplication part

$Q_{i j}^{(2)}=\prod_{j=1}^{n}\left(\bar{x}_{i j}\right)^{w_{i j}}$

Step 3: Joint general criteria of a weighted combination of additive and multiplicative methods

$Q_{i}=0.5 Q_{i j}^{(1)}+0.5 Q_{i j}^{(2)}$

$=0.5 \sum_{j=1}^{n} w_{j} \bar{x}_{i j}+0.5 \prod_{j=1}^{n}\left(\bar{x}_{i j}\right)^{w_{i j}}$

WASPAS approach has been effectively applied in the areas of, making the decision for site selection for a particular project, valuation of safety and health solutions at manufacturing, industrial or a construction site [21] [22] and [23].

\section{Technique for order of preference by similarity to ideal solution (TOPSIS)}

TOPSIS is grounded on the idea that a certain attribute must have the least and farthest remoteness from the positive best result and he negative best result respectively [24], [25], [26], [27] [3], [28] and [29]. The steps involved in TOPSIS method are as follows:

Step 1: To prepare a decision matrix comprising of ' $n$ ' criteria and ' $\mathrm{m}$ ' attributes with the crossing of individual alternative and criterion given as $X_{i j}$, a matrix of $\left(X_{i j}\right)_{m \times n}$ is formed.

Here, $X_{i j}$ is the performance of the $i^{t h}$ attribute in reference with $j^{\text {th }}$ criteria.

Step 2: To construct a normalized judgement matrix (NJM) as (16)

$$
N J M=\frac{X_{i j}}{\sum_{i=1}^{m} X_{i j}^{2}}
$$

Step 3: To obtain a weighted judgement matrix (WJM)

The weighted judgement matrix is obtained from the product of the weights $\left(w_{j}\right)$ calculated for the alternatives available to each element in the column of the normalized judgement matrix.

$W J M=V_{i j}=w_{j} \times N J M$

Step 4: To find an ideal positive and negative solution.

The ideal positive solution is given by (18)

$I P S=A^{+}=\left\{V_{1}^{+}, V_{2}^{+}, \ldots, V_{n}^{+}\right\}$

Where, $V_{j}^{+}=\left\{\max \left(V_{i j}\right)\right.$ if $j \in J ; \min \left(V_{i j}\right)$ if $\left.j \in J^{\prime}\right\}$

Similarly,

The ideal negative solution is given by (19)

INS $=A^{-}=\left\{V_{1}^{-}, V_{2}^{-}, \ldots, V_{n}^{-}\right\}$

Where, $V_{j}^{-}=\left\{\min \left(V_{i j}\right)\right.$ if $j \in J ; \max \left(V_{i j}\right)$ if $\left.j \in J^{\prime}\right\}$

Here, $J$ is related to profit alternatives and $J^{\prime}$ is assigned to non-profit alternatives.

Step 5: To find the parting distance of individual alternative from the positive ideal and negative ideal is

$S^{+}=\sqrt{\sum_{j=1}^{n}\left(V_{j}^{+}-V_{i j}^{+}\right)^{2}}$

Similarly,

$S^{-}=\sqrt{\sum_{j=1}^{n}\left(V_{j}^{-}-V_{i j}^{+}\right)^{2}}$ 
Step 6: To find the comparative distance of each alternative from the ideal solution obtained.

$$
C_{i}=\frac{S_{i}}{S_{i}^{+}+S_{i}^{-}}
$$

Step 7: To assign the ranks for the alternatives as per $\mathrm{C}_{\mathrm{i}}$ values for assessing the performance.

\section{Preference ranking organization method for enrichment evaluation (PROMETHEE)}

This method is created on the approach of the inclination function. Mathematically, a preference function $P_{j}(a, b)$ depends on the pairwise variation, $d_{j}$ between the calculations $f_{j}(a)$ and $f_{j}(b)$ of attributes, a and $\mathrm{b}$ for criterion $\mathrm{j}$, chosen criterion function and corresponding parameters. Similarly parameter $q_{j}$ characterizes the threshold that signifies the largest difference which is taken negligible by the decision-maker while comparing different alternatives on that criterion; parameter $p_{j}$ represents the smallest difference that justifies a strict preference for one of the two alternatives.

Step 1: To derive normalized evaluation matrix;

For beneficial criteria

$$
R_{i j}=\frac{\left[x_{i j}-\min \left(x_{i j}\right)\right]}{\left[\max \left(x_{i j}\right)-\min \left(x_{i j}\right)\right]}
$$

For non-beneficial criteria

$$
R_{i j}=\frac{\left[\max \left(x_{i j}\right)-x_{i j}\right]}{\left[\max \left(x_{i j}\right)-\min \left(x_{i j}\right)\right]}
$$

Step 2: To calculate the evaluative differences of $i^{\text {th }}$ substitute with respect to all other available alternatives as per (25)

$$
D=\left(x_{i 1-} x_{i 2}, x_{i 1-} x_{i 3}, \ldots, x_{i 1-} x_{i j}\right)
$$

Step 3: To determine the preference function $P_{j}(a, b)$

If, $D \leq 0$ then; $P_{j}(a, b)=0$ else, $P_{j}(a, b)=D$

Step 4: To determine aggregated preference as per (26)

$\pi(a, b)=\frac{\sum_{j=1}^{n} w_{j} P_{j}(a, b)}{\sum_{j=1}^{n} w_{j}}$

Step 5: To determine the leaving and the entering outranking flows

$$
\begin{array}{ll}
\text { a) } & \text { For leaving flow } \\
\phi^{+}(a)= & \frac{\sum_{b=1}^{m} \pi(a, b)}{m-1}
\end{array}
$$

b) For entering flow

$\phi^{-}(a)=\frac{\sum_{b=1}^{m} \pi(b, a)}{m-1}$

Step 6: To determine the net outranking flow for each alternative

$$
\phi(a)=\phi^{+}(a)-\phi^{-}(a)
$$

Step 7: To assign ranks to all alternatives as per $\phi(a)$ values for evaluating the performance.

\section{STUDY AREA AND DATA COLLECTION}

This section presents an overview of the study area and data collection. The hydropower projects chosen for the present study are (i) Indira Sagar Project (ISP), with a gross storage volume of 12.22 billion cubic meters $\left(\mathrm{Bm}^{3}\right)$ is situated in Narmada Nagar, a town of district Khandwa of Madhya Pradesh in India at $22.2838^{\circ} \mathrm{N}$ and $76.4715^{\circ} \mathrm{E}$. ISP is the largest reservoir in India. ISP is a multipurpose project and acts as a mother for all other projects on Narmada basin in its downstream. With an installed hydropower capacity of 1000 MW (8*125 MW) commissioned in the year 2005, the powerhouse is a surface type. ISP is capable of annual irrigation for 1.69 lakh hectare in the villages of the districts Khargone, Khandwa and Barwani. Also, meets the demand of $74 \mathrm{MCM}$ for the industrial and domestic requirements in the region.

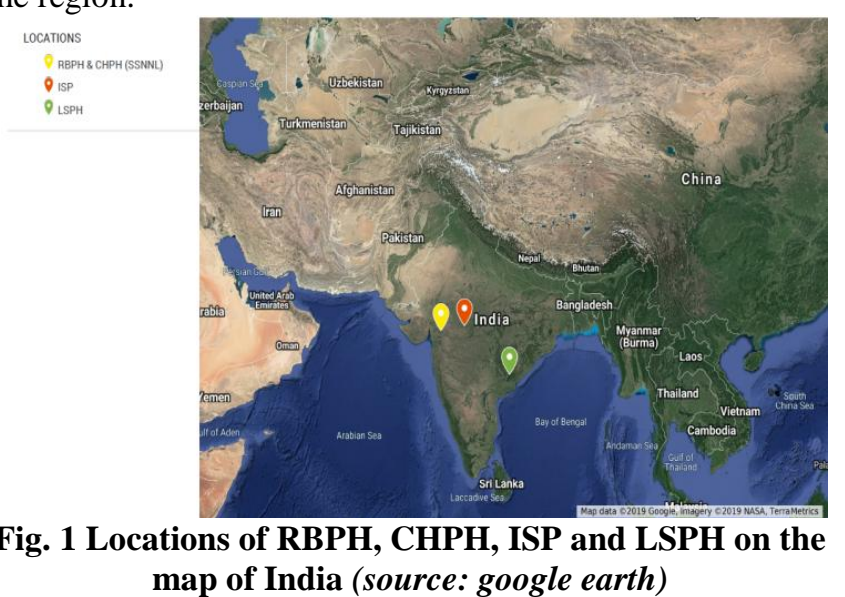

(ii) River bed powerhouse (RBPH) which is an underground type powerhouse having an installed capacity of $1200 \mathrm{MW}$ (6 No. s of 200 MW each) and (iii) Canal head powerhouse (CHPH) with an installed capacity of $250 \mathrm{MW}(5 * 50 \mathrm{MW})$ which is a surface type powerhouse, that receives water, before it is being released in to the canals for the purpose of irrigation. Both RBPH and CHPH powerhouses are at Sardar Sarovar Narmada Nigam Ltd. (SSNNL) which is situated in Navagam village of town Kevadiya colony, in Narmada district of Gujarat in India at $21.8305^{\circ} \mathrm{N}, 73.7485^{\circ} \mathrm{E}$. SSNNL being capable of producing 1450 MW. SSNNL is one of the largest multi-purpose reservoirs in the country, whose benefits are being received amongst four states namely Gujarat, Madhya Pradesh, Maharashtra and Rajasthan. The power produced at RBPH \& CHPH is shared amongst the states of Madhya Pradesh, Gujarat and Maharashtra. (iv) Lower Sileru powerhouse (LSPH) with an installed capacity of $460 \mathrm{MW}$ is situated in the middle of a thick forest, adjacent to East Godavari and Vishakhapatnam districts of state Andhra Pradesh and Khammam a district of state Telangana in India. LSPH was planned in order to utilize the potential energy at Donkarayi reservoir through a $15.6 \mathrm{~km}$ long power canal. The drop in the head between Donkarayi to Khammam is employed, for the power generation.

These projects are chosen for their variety in the operation for power generation, apart from that these projects belong to different classes of hydropower plants. The hydrological and power-house data have been acquired with the help of the officials working at these projects for the last 15 to 20 years. 
In the process of the performance evaluation of a hydropower project, performance affecting criteria are to be chosen, on the background of ample literature survey, field visits to the hydro-power projects and interview with the experts. On account of these criteria and their individual weights, the performance is evaluated. The criteria are; operating head $\left(\mathrm{C}_{1}\right)$, discharge provided to the turbines $\left(\mathrm{C}_{2}\right)$, head loss $\left(\mathrm{C}_{3}\right)$, overall efficiency $\left(\mathrm{C}_{4}\right)$, number of turbines $\left(\mathrm{C}_{5}\right)$, generation cost per unit $\left(\mathrm{C}_{6}\right)$, and auxiliary consumption by the machines $\left(\mathrm{C}_{7}\right)$. Fig. 2 shows the procedure adopted for the present study.

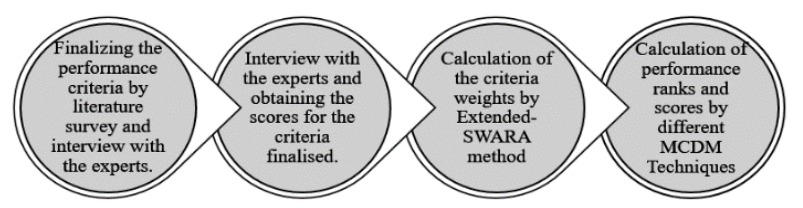

Fig. 2 Flow diagram of the processes involved.

\section{A. Stepwise weight assessment ratio analysis (SWARA)}

For the assessment of weights, the extended SWARA method, as described in part A of section II is used because of its newness and the ability to assess expert's views on the significant proportion amongst the available alternatives, it is

\section{RESULTS AND DISCUSSIONS}

unfussy, user-friendly and straight-forward with which experts may work with ease and this technique also examines the problem on the basis of company policies. The extended SWARA is preferred over other available weighing techniques, because of said merits and novelty. Fourteen experts have participated in this research values for the statistical processing $\mathrm{t}_{\mathrm{jk}}$ were obtained by the interview.

The algorithm for creating criteria weights and the calculation process is presented in Table 1 by using (1) to (9). Thereafter, a priority rank for all the weights is obtained. In this process, the experts' opinions should agree with $\left(\chi_{\alpha, \vartheta}^{2}>\right.$ $\left.\chi_{t b l}^{2}\right)$.

This suggests whether to accept the hypothesis on the rank's correlation or not. From the scores and initial calculations it is understood that, the importance and the weight of the criteria are in the order of overall efficiency $\left(\mathrm{C}_{4}\right)$, followed by generation cost per unit $\left(\mathrm{C}_{6}\right)$, discharge being provided to the turbines for the hydropower generation $\left(C_{2}\right)$, operating head $\left(C_{1}\right)$, number of turbines $\left(C_{5}\right)$, auxiliary consumption by the machines $\left(\mathrm{C}_{7}\right)$ and lastly head lost $\left(\mathrm{C}_{3}\right)$. This preference is considered in further steps of SWARA. Role of the expert is very significant in reassessing and correcting the weights, which were previously calculated using (2) and are shown in Table-I.

Table- I: Parameter prioritization process using the algorithm of parameter weights

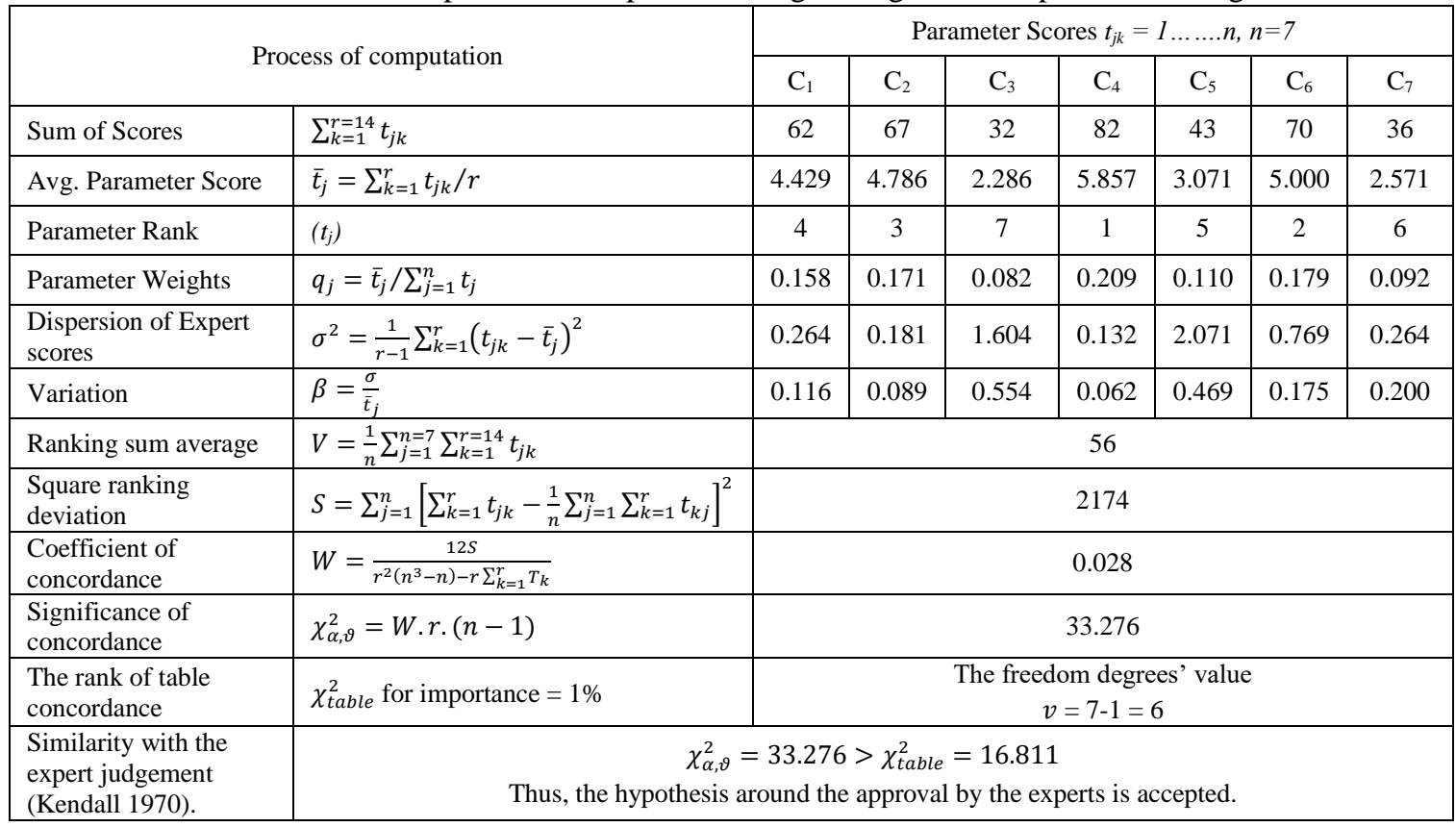

Starting with $\mathrm{j}$ criteria in the attribute ranking order each expert selects the importance of it over $j$ - 1 criteria. Next, each professional assigns a rank to all these criteria from the initial to the latter. On this basis, the utmost important criterion is assigned with $1^{\text {st }}$ rank, and the least important criterion is given the last rank. The overall rank assigned by the group of professionals were obtained, as per the average values of scores. The recalculated weights of all seven criteria are shown in Table-II as $w_{j}$.

Table-II: Weights of criteria using SWARA method

\begin{tabular}{|c|c|c|c|c|}
\hline & $\begin{array}{c}\text { Comparative } \\
\text { importance }\end{array}$ & $\begin{array}{c}\text { Coefficient } \\
\text { for weight } \\
\text { recalculation }\end{array}$ & $\begin{array}{c}\text { Recalculated } \\
\text { Weights }\end{array}$ & $\begin{array}{c}\text { Final } \\
\text { Weights }\end{array}$ \\
\cline { 2 - 5 } & $s_{j}$ & $k_{j}=s_{j}+1$ & $q_{j}=q_{j-1} / k_{j}$ & $\begin{array}{c}w_{j}= \\
q_{j} / \sum_{j=1}^{n} q_{j}\end{array}$ \\
\hline$C_{4}$ & - & 1 & 1 & 0.230 \\
\hline
\end{tabular}

It is observed that the final weights of the criteria are $w_{1}=$ $0.167, w_{2}=0.182, w_{3}=0.065, w_{4}=0.230, w_{5}=0.092, w_{6}=$ 0.191 , and $w_{7}=0.074$. 


\section{B. Integrated SWARA-WASPAS method}

Weights calculated as per Table-I and Table-II, are taken for the assessment of performance ranks of the four alternatives by WASPAS method. Six experienced professionals have participated in this research and have given their input (scores) for the various alternatives. The criterion is marked with the desirable values either ' $m i n$ ' for minimum or non-beneficial criteria and 'max' for maximum or beneficial criteria. The input scores are obtained by interviewing the experts. Further, as shown in B of Section 2 normalization of the decision matrix for WASPAS method using (11) and (12). Followed by, the preparation of the weighted decision matrix is prepared for summarizing and multiplication part is obtained using (13) and (14). From the weighted decision matrix for summarizing part as well as multiplication part and using (15), the final results obtained by WASPAS method are tabulated in Table-III.

Table-III: Results obtained by integrated

SWARA-WASPAS method

\begin{tabular}{|c|c|c|c|c|}
\hline & $\begin{array}{c}\text { Summarizing } \\
\text { Part }\end{array}$ & $\begin{array}{c}\text { Multiplication } \\
\text { Part }\end{array}$ & Sum of both & \multirow{2}{*}{ Rank } \\
\cline { 2 - 4 } & $\mathbf{0 . 5} \sum_{\boldsymbol{j} \mathbf{1}}^{N} \overline{\overline{\boldsymbol{x}}}_{\boldsymbol{i} \boldsymbol{j}}$ & $\mathbf{0 . 5} \prod_{\boldsymbol{j}=\mathbf{1}}^{\boldsymbol{N}} \overline{\boldsymbol{x}}_{\boldsymbol{i} \boldsymbol{j}}$ & $\mathbf{W S P}_{\mathbf{i}}$ & \\
\hline ISP & 2.966 & 0.460 & 3.427 & 1 \\
\hline CHPH & 2.186 & 0.059 & 2.245 & 3 \\
\hline RBPH & 2.251 & 0.082 & 2.332 & 2 \\
\hline LSPH & 2.023 & 0.032 & 2.055 & 4 \\
\hline
\end{tabular}

It can be seen that the final ranks of the alternatives are as ISP (1st), CHPH (3rd), RBPH (2nd) and LSPH (4th).

\section{Integrated SWARA-TOPSIS method}

For the performance evaluation of the available alternatives by TOPSIS method a matrix comprising of, all 4 alternatives and 7 criterion $\left(X_{i j}\right)_{4 \times 7}$ is formed for the average values of the available data for F. Y. 2009-10 to F. Y. 2017-18 demonstrated in Table-IV.

Table-IV: Evaluation matrix for integrated SWARA-TOPSIS method

\begin{tabular}{|l|c|c|c|c|c|c|c|}
\hline & $\mathbf{C}_{1}$ & $\mathbf{C}_{\mathbf{2}}$ & $\mathbf{C}_{\mathbf{3}}$ & $\mathbf{C}_{\mathbf{4}}$ & $\mathbf{C}_{\mathbf{5}}$ & $\mathbf{C}_{\mathbf{6}}$ & $\mathbf{C}_{\mathbf{7}}$ \\
\hline ISP & 54.47 & 3270.40 & 8 & 84.07 & 0.98 & 2.59 & 1.89 \\
\hline CHPH & 28.00 & 8673.76 & 5 & 84.00 & 1.03 & 2.32 & 0.935 \\
\hline RBPH & 101.38 & 8890.93 & 6 & 86.50 & 0.92 & 2.56 & 2.11 \\
\hline LSPH & 141.82 & 2822.13 & 4 & 6.63 & 2.91 & 2.15 & 3.86 \\
\hline
\end{tabular}

The further steps involved this method which is illustrated in $\mathrm{C}$ of Section 2 using (16) to (22). The final performance scores or ranks are obtained by integrated SWARA-TOPSIS method are demonstrated in Table- $\mathrm{V}$.

Table-V: Euclidean distance, performance scores and rankings by SWARA-TOPSIS method

\begin{tabular}{|c|c|c|c|c|c|}
\hline & $\begin{array}{c}\text { Distanc } \\
\text { e from } \\
\text { Ideal } \\
\text { (Best) }\end{array}$ & $\begin{array}{c}\text { Distanc } \\
\text { e from } \\
\text { Ideal } \\
\text { (Worst) }\end{array}$ & $\begin{array}{c}\text { Sum of } \\
\text { Euclidea } \\
\text { n } \\
\text { Distance }\end{array}$ & $\begin{array}{c}\text { Performance } \\
\text { Score }\end{array}$ & $\begin{array}{c}\text { Rank } \\
\text { s }\end{array}$ \\
\cline { 2 - 5 } ISP & 0.0814 & 0.1572 & 0.2386 & 0.6589 & 1 \\
\hline $\begin{array}{c}\boldsymbol{S}_{\boldsymbol{j}}^{+} \\
\text {H }\end{array}$ & 0.1333 & 0.1340 & 0.2673 & 0.5012 & 3 \\
\hline RBPH & 0.0951 & 0.1506 & 0.2457 & 0.6131 & 2 \\
\hline LSPH & 0.1413 & 0.1335 & 0.2748 & 0.4856 & 4 \\
\hline
\end{tabular}

It can be seen that the final ranks of the alternatives are as ISP $\left(1^{\text {st }}\right)$, CHPH $\left(3^{\text {rd }}\right), \operatorname{RBPH}\left(2^{\text {nd }}\right)$ and LSPH $\left(4^{\text {th }}\right)$ which matches with the results that are obtained by the integrated SWARA-WASPAS method.

\section{Integrated SWARA-PROMETHEE method}

The prioritization of the criterion based on beneficial (Max) and non-beneficial (Min) as done previously for WASPAS method is made. Evaluation matrix for the computation of ranks by PROMETHEE method is same as that for TOPSIS method and is shown previously in Table-IV, while the normalized evaluative matrix is calculated on the basis of (23) and (24).

In the procedure steps to follow the evaluative difference of $\mathrm{i}^{\text {th }}$ alternative with respect to all other available alternatives are calculated as per (25). Followed by the determination of the aggregated preference using (26). Further, the weighted aggregate preference function is identified for leaving and entering outflows with the help of (27) and (28) respectively. Lastly, the final performance ranks are calculated as net outranking flows as per (29). The final performance ranks are revealed in the Table-VI.

Table-VI: Final ranks obtained by integrated SWARA-PROMETHEE method

\begin{tabular}{|c|c|c|c|}
\hline Leaving & Entering & Leaving-Entering & Rank \\
\hline 0.1377 & 0.3602 & -0.2225 & 4 \\
\hline 0.3113 & 0.1903 & 0.1211 & 2 \\
\hline 0.3891 & 0.0796 & 0.3095 & 1 \\
\hline 0.2850 & 0.4931 & -0.2081 & 3 \\
\hline
\end{tabular}

The final ranks of the alternatives are as ISP (4th), CHPH (2nd), RBPH (1st) and LSPH (3rd).

Table-II illustrates the results of criteria weights of the performance affecting parameters which are determined by using extended SWARA method. These weights were used to assess the performance ranks of by integrated SWARA-WASPAS, SWARA-TOPSIS and SWARA-PROMETHEE approaches. The final performance ranks achieved by these three methods are shown in individually Table-III, Table-V and Table-VI respectively.

For the better understanding and comparison of the three methods, a combined table of the performance ranks so obtained by the three methods is prepared and demonstrated in Table-VII.

Table-VII: Combined performance ranks obtained by three methods (SWARA-WASPAS, SWARA-TOPSIS and SWARA-PROMETHEE)

\begin{tabular}{|c|c|c|c|}
\hline $\begin{array}{c}\text { Altern } \\
\text { atives }\end{array}$ & $\begin{array}{c}\text { SWARA- } \\
\text { WASPAS }\end{array}$ & $\begin{array}{c}\text { SWARA- } \\
\text { TOPSIS }\end{array}$ & $\begin{array}{c}\text { SWARA-PRO } \\
\text { METHEE }\end{array}$ \\
\hline ISP & 1 & 1 & 4 \\
\hline $\mathrm{CHPH}$ & 3 & 3 & 2 \\
\hline $\mathrm{RBPH}$ & 2 & 2 & 1 \\
\hline $\mathrm{LSPH}$ & 4 & 4 & 3 \\
\hline
\end{tabular}

Table-VII helps in understanding that the final performance ranks obtained by the integrated methods of SWARA-WASPAS and SWARA-TOPSIS are same and indicates the working conditions, as well as the performance of ISP, is best amongst the other alternatives followed by $\mathrm{RBPH}, \mathrm{CHPH}$ and lastly LSPH. Whereas the performance of ISP is adjudged as worst by SWARA-PROMETHEE approach. 


\section{CONCLUSION}

The inconsistency in the performance ranks is because of the difference in the approaches of these methods, where TOPSIS aims to identify Euclidean distance (i.e. the distance of a particular attribute from an ideal solution as well as ideal negative), unlike PROMETHEE, which gives the preference to the peak values and does not consider for an ideal solution. While, for the WASPAS method it facilitates an individual to express their views and apply their knowledge, in the form of their inputs for the available data, performances, working conditions and the age of the project.

The efficiency of the hydropower plants can be improved and controlled by timely performance assessment, timely maintenance, repairs and replacement if required as prescribed by an expert team. Under the consequences of continuous running, every power plant has to undergo some repair and maintenance works from its year of installation, this may affect the performance of the hydropower plant. Better is the understanding of the issues with the conditions of the hydropower plants, better would be the emergence of best practices for improving the performance of the plants. Timely evaluation is desired to rectify the problem of ageing and deterioration.

Based on the results obtained in the present research by the integrated SWARA-WASPAS and SWARA-TOPSIS method the final ranks obtained are as ISP $\left(1^{\text {st }}\right)$, CHPH $\left(3^{\text {rd }}\right)$, RBPH $\left(2^{\text {nd }}\right)$ and LSPH $\left(4^{\text {th }}\right)$ while for SWARA-PROMETHEE method the ranks are ISP $\left(4^{\text {th }}\right)$ CHPH $\left(2^{\text {nd }}\right)$ RBPH $\left(1^{\text {st }}\right)$ LSPH $\left(3^{\text {rd }}\right)$. On comparing the final performance ranks obtained by these three methods, it is concluded that the results obtained by the SWARA-WASPAS and SWARA-TOPSIS methods are much similar to the on-field data available for the tenure F. Y. 2009-10 to F.Y. 2017-18 and is accepted for the present study.

In addition, a new study may be developed which could focus on the use of other MCDM methods like VIKOR, ELECTRE, ARAS, and ANP, etc. and relate that with the results of this paper.

\section{ACKNOWLEDGMENT}

The help, support and backing rendered by Shri. Anurag Seth (Head of Project) and other administrative staff of ISP, Narmada Nagar, district Khandwa, Shri. Anurag Ojha, Narmada Hydroelectric Development Corporation (NHDC) Bhopal, Shri Ashok V. Gajjar (Retd. Executive Engineer, SSNNL) is hereby acknowledged for acquiring the hydrological data for the period financial year (F.Y.) 2009-10 to 2017-18. As well as in finalizing performance evaluation parameters and calculation of weights.

\section{REFERENCES}

1. Agency, I. E. (2018). Renewables 2018. doi:10.1787/re_mar-2018-en

2. Boran, K. (2017). An evaluation of power plants in Turkey: Fuzzy TOPSIS method. Energy Sources, Part B: Economics, Planning and Policy, 12(2), 119-125. doi:10.1080/15567249.2015.1050561

3. Calamak, M., \& Bozkus, Z. (2013). Comparison of Performance of Two Run-of-River Plants during Transient Conditions. Journal of Performance of Constructed Facilities, 27(5), 624-632. doi:10.1061/(ASCE)CF.1943-5509.0000370

4. CHAKRABORTY, S., \& ZAVADSKAS, E. K. (2014). Applications ofWASPAS Method in Manufacturing Decision Making. Informatica, 25(1), 1-20. doi:10.15388/Informatica.2014.01

5. Cordova, M. M., Finardi, E. C., Ribas, F. A. C., de Matos, V. L., \&
Scuzziato, M. R. (2014). Performance evaluation and energy production optimization in the real-time operation of hydropower plants. Electric Power Systems Research, 116, 201-207. doi:10.1016/j.epsr.2014.06.012

6. Dejjus, T., \& Antuchevičienè, J. (2013). Assessment of health and safety solutions at a construction site. Journal of Civil Engineering and Management, 19(5), 728-737. doi:10.3846/13923730.2013.812578

7. Ghosh, Santosh, Mali, S., \& Kshirsagar, J. (2010). Performance testing of a low head small hydro power plant - Zho Suwei (Taiwan), 44-54.

8. Ghosh, Soumya, Majumder, M., \& Pal, M. (2017). Development of performance index for evaluation of small scale hydro power plants by neural network and multi criteria decision making. International Journal of Energy and Statistics, 04(04), 1650019. doi:10.1142/s2335680416500198

9. Hashemkhani Zolfani, S., Aghdaie, M. H., Derakhti, A., Zavadskas, E. K., \& Morshed Varzandeh, M. H. (2013). Decision making on business issues with foresight perspective; An application of new hybrid MCDM model in shopping mall locating. Expert Systems with Applications, 40(17), 7111-7121. doi:10.1016/j.eswa.2013.06.040

10. Hashemkhani Zolfani, S., Yazdani, M., \& Zavadskas, E. K. (2018). An extended stepwise weight assessment ratio analysis (SWARA) method for improving criteria prioritization process. Soft Computing, 22(22), 7399-7405. doi:10.1007/s00500-018-3092-2

11. Hatami-Marbini, A., \& Kangi, F. (2017). An extension of fuzzy TOPSIS for a group decision making with an application to Tehran stock exchange. Applied Soft Computing Journal, 52, 1084-1097. doi:10.1016/j.asoc.2016.09.021

12. Ijadi Maghsoodi, A., Ijadi Maghsoodi, A., Mosavi, A., Rabczuk, T., \& Zavadskas, E. (2018). Renewable Energy Technology Selection Problem Using Integrated H-SWARA-MULTIMOORA Approach. Sustainability, 10(12), 4481. doi:10.3390/su10124481

13. Keršulienè, V., Zavadskas, E. K., \& Turskis, Z. (2010). Selection of Rational Dispute Resolution Method By Applying New Step-Wise Weight Assessment Ratio Analysis (Swara). Journal of Business Economics and Management, 11(2), 243-258. doi:10.3846/jbem.2010.12

14. Kolios, A., Mytilinou, V., Lozano-Minguez, E., \& Salonitis, K. (2016) A comparative study of multiple-criteria decision-making methods under stochastic inputs. Energies, 9(7), 1-21. doi:10.3390/en9070566

15. Kuo, T. (2017). A modified TOPSIS with a different ranking index. European Journal of Operational Research, 260(1), 152-160. doi:10.1016/j.ejor.2016.11.052

16. Majumder, M. (2015). Impact of Urbanization on Water Shortage in Face of Climatic Aberrations, 35-48. doi:10.1007/978-981-4560-73-3

17. ÖZCAN, E. C., \& EREN, T. (2014). Application of TOPSIS Method for Maintenance Planning: Natural Gas Combined Cycle Power Plant Case Study. Uluslararasi Muhendislik Arastirma ve Gelistirme Dergisi, 6(2), 26-38. doi:10.29137/umagd.346087

18. Özcan, E. C., \& Erol, S. (2014). A multi-objective mixed integer linear programming model for energy resource allocation problem: The case of turkey. Gazi University Journal of Science, 27(4), 1157-1168.

19. Özcan, E. C., Ünlüsoy, S., \& Eren, T. (2017). A combined goal programming - AHP approach supported with TOPSIS for maintenance strategy selection in hydroelectric power plants. Renewable and Sustainable Energy Reviews, 78(May 2016), 1410-1423. doi:10.1016/j.rser.2017.04.039

20. Panahi, S., Khakzad, A., \& Afzal, P. (2017). Application of stepwise weight assessment ratio analysis (SWARA) for copper prospectivity mapping in the Anarak region, central Iran. Arabian Journal of Geosciences, 10(22), 1-17. doi:10.1007/s12517-017-3290-8

21. Rana, S. C., \& Patel, J. N. (2018). Selection of best location for small hydro power project using AHP, WPM and TOPSIS methods. ISH Journal of Hydraulic Engineering, 5010(May), 1-5. doi:10.1080/09715010.2018.1468827

22. Sharma, A. K., \& Thakur, N. S. (2016). Analyze the factors effecting the development of hydro power projects in hydro rich regions of India. Perspectives in Science, 8, 406-408. doi:10.1016/j.pisc.2016.04.090

Published By:

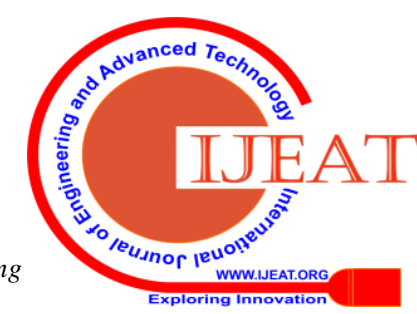


23. Shimray, B. A., Singh, K. M., Khelchandra, T., \& Mehta, R. K. (2017). Ranking of Sites for Installation of Hydropower Plant Using MLP Neural Network Trained with GA: A MADM Approach. Computational Intelligence and Neuroscience, 2017. doi:10.1155/2017/4152140

24. Si, Y., Li, X., Yin, D., Liu, R., Wei, J., Huang, Y., ... Wang, G. (2018). Evaluating and optimizing the operation of the hydropower system in the Upper Yellow River: A general LINGO-based integrated framework. PLoS ONE, 13(1), 1-25. doi:10.1371/journal.pone.0191483

25. Siksnelyte, I., Zavadskas, E. K., Streimikiene, D., \& Sharma, D. (2018). An overview of multi-criteria decision-making methods in dealing with sustainable energy development issues. Energies, 11(10). doi:10.3390/en11102754

26. Singh, V. K., \& Singal, S. K. (2018). Application of MADM for Assessment of Parameters for Optimum Operation of small Hydropower Plants, (July 2017).

27. Walczak, D., \& Rutkowska, A. (2017). Project rankings for participatory budget based on the fuzzy TOPSIS method. European Journal of Operational Research, 260(2), 706-714. doi:10.1016/j.ejor.2016.12.044

28. Wang, B., Nistor, I., Murty, T., \& Wei, Y. M. (2014). Efficiency assessment of hydroelectric power plants in Canada: A multi criteria decision making approach. Energy Economics, 46, 112-121. doi:10.1016/j.eneco.2014.09.001

29. Zyoud, S. H., \& Fuchs-Hanusch, D. (2017). A bibliometric-based survey on AHP and TOPSIS techniques. Expert Systems with Applications, 78, 158-181.

doi:10.1016/j.eswa.2017.02.016

\section{AUTHORS PROFILE}

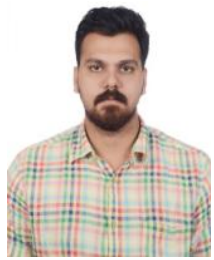

Sushrut H. Vinchurkar is presently a $\mathrm{PhD}$ research scholar in the Department of Civil Engineering at Sardar Vallabhbhai National Institute of Technology, Surat. Prior to joining PhD program in the full-time category, the author has obtained his bachelor's in engineering degree from Sanghvi Innovative Academy, Indore (Affiliated to

Rajiv Gandhi Prodyogiki Vishwavidyalaya, Bhopal.) in the year 2012 and masters' in engineering with specialization in water resources engineering from Shri. G. S. Institute of Technology and Science, Indore (Affiliated to Rajiv Gandhi Prodyogiki Vishwavidyalaya, Bhopal.) in the year 2014. After completing the masters the author has worked as an Asst. Prof in the Civil Engineering Department at Swami Vivekanand College of Engineering, Indore for 2 years.

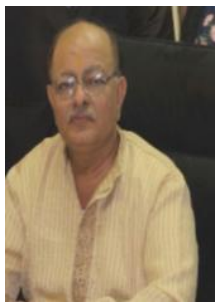

B.K. Samtani, currently working as a Professor in the Department of Civil Engineering at Sardar Vallabhbhai National Institute of Technology, Surat is currently teaching subjects like Fluid Mechanics, Advanced Fluid Mechanics, Water Resources Engineering, Hydraulics of Alluvial River, Open Channel Flow, Water Resources System, Hydro Power Engineering at UG and PG level. Prof. Samtani has a vast experience of 35 years in the field of academics, research and consultancy. Prof. Samtani has undertaken 12 research works which have 13 citations and 313 reads. Prof. Samtani has been the Head of Civil Engineering Department from 2008-11 and also was Dean (Examination) for more than 3 years from 2005-08. Prof. Samtani has successfully supervised $3 \mathrm{PhD}$ candidates, and currently supervising $3 \mathrm{PhD}$ in full-time category and 3 in the part-time category. He is the life-member of more than 5 well known technical society. 